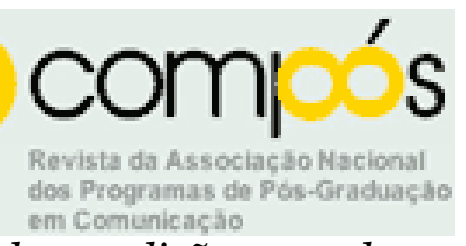

Este artigo foi publicado na edição 1, em dezembro de 2004, da revista eletrônica e-compós: http://www.compos.org.br/e-compos

\title{
AS FRONTEIRAS ENTRE AS CIÊNCIAS SOCIAIS VISTAS DA COMUNICAÇÃO: UMA APROXIMAÇÃO AOS ESTUDOS SOCIAIS DAS CIÊNCIAS
}

Maria Immacolata Vassallo de Lopes ${ }^{1}$

USP

Dividimos e relacionamos o saber de três modos distintos:

intelectualmente como disciplinas; organizacionalmente como

estruturas corporativas; e culturalmente como comunidades

de estudiosos que compartilham certas premissas básicas.

Immanuel Wallerstein.

Acho que o inconsciente de uma disciplina é a sua história;

as condições sociais de produção ocultadas, esquecidas, são

o inconsciente: o produto separado de suas condições sociais

de produção muda de sentido e exerce um efeito ideológico.

Pierre Bourdieu

Inscrever na ordem do dia a multidisciplinaridade.

Não aquela das grandes construções prometéicas de

uma nova Enciclopédia, mas aquela que provoca o

\footnotetext{
${ }^{1}$ Maria Immacolata Vassallo de Lopes é Livre-docente da Escola de Comunicações e Artes da USP, coordenadora do Programa de Pós-Graduação de Comunicação da USP; representante da área de Comunicação no CNPq; leciona metodologia da pesquisa em Comunicação na graduação e pósgraduação; principais publicações: Pesquisa em

Comunicação. São Paulo: Loyola, 2003, $7^{\mathrm{a}}$ ed.;Vivendo com a telenovela. São

Paulo: Summus, 2002; Comunicación: campo y objeto de estudio (org.) México, ITESO, 2001;

Epistemologia da Comunicação (org.). São Paulo:Loyola, 2002; Telenovela, internacionalização e interculturalidade (org.). São Paulo: Loyola, 2004.
} 
encontro ao redor de um mesmo objeto de estudo de

pesquisadores pertencendo a metodologias múltiplas.

Estabelecer com eles alianças, aproveitando o

prestígio atual da comunicação e prevenindo-se

contra as tendências à hegemonia das antigas disciplinas.

Armand Mattelart

\section{Resumo}

A origem de campos de estudos como a Comunicação provém de um duplo movimento. O primeiro é um movimento interno da própria ciência que é de convergência e de sobreposição de conteúdos e metodologias, e que se faz notar de forma crescente no desenvolvimento histórico recente das Ciências Sociais. O segundo é o movimento de ruptura histórica ocasionado pelo que se convencionou chamar de processo de globalização.

No presente texto, damos seguimento a reflexões anteriores, para agora enfocar o duplo movimento acima assinalado, problematizando : 1) a disciplinarização que norteou o nascimento e desenvolvimento das Ciências Sociais com base na concepção de disciplina como constructo epistemológico do século XIX ; 2) a sociedade global como sociedade da comunicação.

\section{A difícil herança do estatuto disciplinar da Comunicação}

A crítica da ciência não é nova. Qualquer estudo é sempre feito dentro dos quadros de referência herdados do passado de uma ciência, do que é sua história ou sua tradição. Porém, os objetos de estudo, por seu caráter histórico, dinâmico e mutável, colocam permanentemente em cheque essa tradição no sentido de sua renovação e revisão. A tradição é vista como um ponto de partida, na qual enraizase a identidade de uma ciência, porém, nunca no sentido fechar um saber, mas de abri-lo para dar continuidade à sua construção, pois um saber não é, em essência, nem estático, nem definitivo. É sobre a tensão constante entre a tradição e a 
mudança no campo científico que reside a base do surgimento de estudos e diagnósticos que buscam sua reestruturação. Como afirma Octavio Ianni: "se as ciências sociais nascem e desenvolvem-se como formas de autoconsciência científica da realidade social, pode-se imaginar que elas podem ser seriamente desafiadas quando essa realidade já não é mais a mesma. O contraponto de pensamento e pensado, ou de lógico e histórico, pode alterar-se um pouco, ou muito, quando um dos termos modifica-se; e mais ainda quando ele se transfigura (Ianni, 1992: 171).

Tomada como novo paradigma histórico-social, a sociedade global produz uma ruptura histórica de amplas proporções e em todas as dimensões. No dizer de Ianni, "com as metamorfoses do 'objeto' e a simultânea alteração das possibilidades que se abrem ao 'sujeito' da reflexão, colocam-se novos desafios não só metodológicos e teóricos, mas também epistemológicos" (Ianni, 1996:34).

Na pesquisa de comunicação, as diversas tradições teórico-metodológicas, tal como nas ciências sociais em escala mais ampla, têm sido postas em revisão nos últimos anos. Em trabalhos anteriores (Lopes, 2000, 2003), registrei o aumento das análises auto-reflexivas no campo da Comunicação. A multiplicação de propostas de reformulação teórica dos estudos da comunicação manifesta uma insatisfação generalizada com o estado atual do campo e a urgência de repensar seus fundamentos e de reorientar o exercício de suas práticas. São análises convergentes, se bem que nem sempre complementares, análises que realizam revisões, redefinições, reestruturações, reinterpretações e rupturas com categorias analíticas, esquemas conceituais, métodos de investigação. Não obstante, são análises reveladoras da complexidade e multidimensionalidade dos fenômenos comunicativos num mundo cada vez mais globalizado, multiculturalizado e tecnologizado, mas também cada vez mais fragmentado e desigual.

O que se nota é um movimento de convergência de saberes especializados sobre a comunicação, entendido mais como movimento de intersecção que não é, em hipótese alguma, uma amálgama ou síntese de saberes. É, antes um produto das relações entre o objeto de estudo, a especificidade das contribuições analíticas e a 
particularidade da evolução histórica entre ambos. São os percursos disciplinares já trilhados nas tradições dos estudos da comunicação que autorizam parafrasear Canclini que diz: "Estudar a (cultura) comunicação requer converter-se num especialista de intersecções" (Canclini, 1999: 69).

Por outro lado, isso significa abrir mão das certezas disciplinares e do poder dado pela ortodoxia, a que Giddens chama de "consenso ortodoxo". Ao contrário, o pensamento heterodoxo impele a estratégias de mudança, como vimos em Bourdieu, e nos leva de volta ao caráter institucional do campo científico.

\section{A institucionalização das Ciências Sociais}

O relatório da Comissão Gulbenkian para a reestruturação das ciências sociais, presidida por Immanuel Wallerstein e intitulado Abrir as ciências sociais (1996) está estruturado ao redor de uma discussão histórica dos processos de disciplinarização das ciências sociais desde o século XVIII até a atualidade.

Há dois pontos polêmicos que constam do Relatório Gulbenkian sobre a reestruturação das ciências sociais.

O primeiro é o de que a divisão interna das ciências sociais em múltiplas disciplinas resultou principalmente de decisões institucionais que quase sempre mantiveram laços fracos com o debate propriamente epistemológico. E o segundo ponto é a proposta de trabalho transdisciplinar com base na crítica da prática interdisciplinar.

O Relatório Gulbenkian tem por base a história dessas ciências feita com base em seu crescente processo de institucionalização e de mudanças nas formas organizativas do trabalho científico. Detém-se nas mudanças ocorridas a partir de 1945, no pós-guerra, com o desenvolvimento da guerra fria, os investimentos no desenvolvimento científico e a concentração dos pólos científicos em alguns países, com a hegemonia dos Estados Unidos. Entre as conseqüências destas mudanças a 
nível mundial sobressai a questão da validade das distinções no interior das ciências sociais, baseada em clivagens estabelecidas pelo paradigma da ciência do século XIX para as então nascentes ciências sociais, passa a ser profundamente contestada. Essas clivagens eram: a) a demarcação entre o estudo do mercado (a economia), do estado (a ciência política) e da sociedade civil (a sociologia); b) a divisão entre o estudo do mundo moderno/ocidental (a economia, sociologia e política) e o mundo não-moderno/não-ocidental (a antropologia); c) do mundo presente (a economia, sociologia e política) e o mundo passado (a história). Posteriormente a 1945, a inovação acadêmica mais importante foi, segundo o relatório, a criação de estudos por áreas ou regiões (URSS, China, América Latina, África, Europa Central, Sudeste Asiático, etc), uma nova categoria institucional (a geográfica) que levou a um reagrupamento do trabalho intelectual. Esses novos estudos por área eram, por definição, "multidisciplinares" e as "motivações políticas subjacente à sua origem eram bastante explícitas (p.6o). Chama-se a atenção para o fato de que os estudos por áreas atraíram para o interior de uma estrutura única pessoas cuja filiação disciplinar atravessava transversalmente as três clivagens já referidas. Cientistas sociais de origens e inclinações diferentes encontraram-se frente a frente com geógrafos, historiadores da arte, estudiosos das literaturas nacionais, epidemiologistas e até geólogos. Passaram a produzir currículos em conjunto, a participar nas bancas de doutoramento dos alunos uns dos outros, a assistir congressos organizados por especialistas de cada área e, principalmente, passaram a ler os livros uns dos outros e a publicar artigos nas novas revistas transdisciplinares de cada especialidade. Estas práticas vieram pôr a nu o muito que havia de artificial nas rígidas divisões institucionais do conhecimento associado às ciências sociais.

Consideramos importante transcrever a avaliação que o Relatório faz desse movimento de convergência e de sobreposição entre as disciplinas. "Não só se tornou cada vez mais complicado achar linhas de diferenciação nítidas entre elas, quer no respeitante ao seu objeto concreto de estudo, quer no que concerne às modalidades de tratamento dos dados, como também sucedeu que cada uma das disciplinas se tornou cada vez mais heterogênea, devido ao alargamento das balizas 
dos tópicos de investigação considerados aceitáveis. Uma das formas de lidar com esta situação foi a tentativa de criar novas designações 'interdisciplinares', como sejam os estudos da comunicação, as ciências da administração e as ciências do comportamento". Estes campos "interdisciplinares" manifestaram um "questionamento interno considerável em torno da coerência das disciplinas e a legitimidades das premissas intelectuais que cada uma delas havia utilizado para defender seu direito a uma existência autônoma" (p.72-3).

O segundo ponto polêmico do Relatório é a proposta de reestruturar as ciências sociais com base no estabelecimento, no interior das estruturas universitárias, de programas integrados de investigação transversais às balizas de demarcação tradicionais, os quais seriam "novas vias de diálogo e de troca para além das disciplinas e não apenas entre elas" (p. 124).

A crítica à interdisciplinaridade é explicita e, não obstante reconhecer-se que se constituiu numa forma de abordagem criativa, ela não teria implicado uma frutuosa fertilização recíproca entre as disciplinas, condição única que faria a interdisciplinaridade merecedora de um maior aprofundamento e desenvolvimento.

Em trabalho anterior, Wallerstein (1991) já criticara os méritos da pesquisa e do ensino interdisciplinar em seu duplo sentido. O primeiro é o da combinação de perspectivas de diversas disciplinas sobre um objeto (por exemplo, o trabalho) e a lógica dessa abordagem leva à formação de uma equipe multidisciplinar ou a um só pesquisador estudando diversas disciplinas relacionadas ao objeto. O segundo sentido é o da localização do objeto nas fronteiras de duas ou mais disciplinas, sendo que a lógica desta abordagem pode dirigir-se eventualmente ao desenvolvimento de uma nova disciplina autônoma (é o que aconteceu com a lingüística, por exemplo).

"Sabe-se que as múltiplas disciplinas existem desde que há múltiplos departamentos acadêmicos nas universidades em todo o mundo, cursos de 
graduação nessas disciplinas e associações nacionais e internacionais de pesquisadores destas disciplinas. Isto é, nós sabemos politicamente que diferentes disciplinas existem. Elas tem uma organização delimitada, estrutura e pessoal para defender seus interesses coletivos e assegurar sua reprodução coletiva. Mas isto nada nos diz acerca da validade das exigências intelectuais da separação, exigências que presumivelmente justificam só a rede organizativa" (Wallerstein, 1991: 239).

Por isso, os méritos do trabalho interdisciplinar nas ciências sociais não chegaram a solapar significativamente a força dos aparatos organizacionais que protegem as disciplinas separadas. E mesmo, o contrário pode ser verdadeiro. Um pesquisador, ao justificar que precisa aprender do outro o que não pode conseguir no seu próprio nível de análise com suas metodologias específicas e que o "outro"conhecimento é pertinente e significante para a resolução dos problemas intelectuais sobre os quais está trabalhando, tende a reafirmar e não a embaralhar os dois conhecimentos. O trabalho interdisciplinar não é, per se, uma crítica da compartimentalização existente nas ciências sociais, além de lhe faltar o toque político para afetar as estruturas institucionais existentes.

Mas, pergunta o autor: as várias disciplinas das ciências sociais são disciplinas?

Etimologicamente, a palavra disciplina é vinculada a discípulo ou estudante e é antitética à doutrina que é a propriedade do doutor ou professor. Portanto, doutrina concerne à teoria abstrata e disciplina é relativa à prática e ao exercício. A primeira tem a ver com a produção e a segunda com a reprodução do conhecimento.

$\mathrm{Na}$ história das ciência sociais, uma disciplina só aparece depois de um longo trajeto de prática quando torna-se doutrina, ensinada e justificada pelos doutores e professores. Mas com isso, pergunta-se o autor, atingiu-se um nível defensável e coerente de análise ou apenas separou-se um assunto? 
Todas as divisões em assuntos derivaram intelectualmente da ideologia liberal dominante no século XIX, que argumentava que o estado e o mercado, a política e a economia, eram setores analiticamente separados, cada um com suas regras ou "lógicas"particulares. Sabemos o que as dificuldades de fronteiras causaram nos itinerários intelectuais dos campos (sociologia, política, economia e antropologia), e que eles foram complexos e variados. Porém como o mundo real evoluiu, a linha de contato entre "primitivo" e "civilizado", "político" e "econômico" embaraçou-se. Invasões intelectuais tornaram-se comuns, porém os invasores moveram as estacas mas não as quebraram.

A questão diante de nós, hoje, é se há algum critério intelectual que possa ser usado para assegurar de um modo relativamente claro e defensável as fronteiras entre as quatro presumidas disciplinas de antropologia, economia, ciência política e sociologia. A "análise do sistema-mundo" (world systems analysis), proposta pelo autor, responde com um inequívoco "não" a esta questão. "Todos os critérios presumidos - nível de análise, objeto, métodos, teorias - ou não são verdadeiros na prática ou, se sustentados, são linhas divisórias para um conhecimento adicional mais do que estímulos para a sua criação" (p. 241).

Ou, colocado de outro modo, as diferenças dentro de uma disciplina tendem a ser maiores do que as diferenças entre elas. Isto quer dizer na prática que a sobreposição é substancial e na histórias desses campos, ela tem crescido todo o tempo. Isto não quer dizer que todos os cientistas sociais devam fazer um trabalho idêntico. Há sempre necessidade de especialização em campos de estudo (fields of inquiry). O autor dá um exemplo esclarecedor de que especialização e disciplinarização não são sinônimos, mas que a Segunda é uma forma própria do século XIX para controlar a primeira. Entre 1945 e 1955, as disciplinas separadas botânica e zoologia fundiram-se em uma única disciplina chamada biologia. Desde então a biologia tem sido uma disciplina florescente e gerou muitos sub-campos mas nenhum que tenha os contorno da botânica ou da zoologia. 
Portanto, os campos de estudo aparecem como um novo padrão emergente a que se pode chamar transdisciplinarização ou pós-disciplinarização (Fuentes, 1998), quer dizer, um movimento para a superação dos limites entre especialidades fechadas e hierarquizadas, e o estabelecimento de um campo de discurso e práticas sociais cuja legitimidade acadêmica e social vai cada vez mais depender da profundidade, extensão, pertinência e solidez das explicações que produza, do que do prestígio institucional acumulado.

Em resumo, a crítica à compartimentação das ciências sociais tem, portanto, a ver com clivagens colocadas por paradigmas histórico-intelectuais do século XIX e que, segundo o Relatório Gulbenkian, são mais clivagens ideológicas e organizativas do trabalho intelectual do que propriamente derivadas de exigências internas do conhecimento, isto é, epistemológicas, teóricas e metodológicas

\section{Sociedade global, Ciências Sociais e Comunicação}

Há, entretanto, outro aspecto que deveria ser acrescentado a esse poderoso argumento. Trata-se da relação orgânica entre as ciências sociais e a comunicação na medida em que a sociedade moderna foi sendo cada vez mais plasmada nas formas da comunicação moderna. Dois exemplos são suficientes: um saber como o da antropologia não seria possível sem o encontro entre civilizações e grupos humanos diferentes em escala cada vez mais intensa e um estudo como o de Habermas sobre a opinião pública revelando a importância desta na constituição da sociedade civil moderna, e a emergência da idéia de esfera pública ligada aos mecanismos da informação e da comunicação social. Daí, no dizer de Vattimo, "as ciências humanas, ciências que nascem de fato somente na modernidade, estão condicionadas, em uma relação de determinação recíproca, pela constituição da sociedade moderna como sociedade da comunicação. As ciências humanas são ao mesmo tempo efeito e meio do posterior desenvolvimento da sociedade da comunicação generalizada" (1992:20-21). Chega-se assim a definir a intensificação dos fenômenos comunicativos, a acentuação da circulação das informações não 
somente como um aspecto a mais da modernização, senão como o próprio centro e o sentido mesmo deste processo.

É no objeto-mundo "com sentido" que as ciências humanas e a comunicação se encontram. No mundo "comunicado", que tanto os media como as ciências humanas nos oferecem, constitui-se a objetividade mesma do mundo e não somente interpretações diferentes de uma "realidade" de alguma maneira "dada". A realidade do mundo como algo que enfim não é uma reunião de visões disciplinares do empirismo ingênuo, mas algo que se constrói como contexto de múltiplas narrativas. Tematizar o mundo nestes termos é precisamente a tarefa e o significado das ciências humanas. É neste sentido também, que o debate metodológico passa a ocupar um amplo espaço nas ciências sociais de hoje, porque discutir a realidade globalizada ou mundializada, como paradigma social e epistemológico, passa a ser uma questão central e substantiva para desdogmatizar as ciências sociais e discutir a própria construção da ciência como discurso. Admitir o caráter intrinsecamente histórico desse discurso (epistemologia histórica de Bachelard) é reconhecer nas ciências sociais as formas de autoconsciência social em que elas sempre se constituiram (Ianni), através da revelação das pluralidades dos mecanismos e das armaduras internas de sua construção.

$\mathrm{Na}$ nova percepção de espaço e o tempo que configura este começo de século desdobra-se um mapa de sintomas e desafios para as Ciências Sociais, uma agenda nova para a investigação (Martín-Brabero, 2001). Especificamente no que aqui tematizamos, na dificuldade das ciências sociais em tratar do fenômeno comunicacional há algo mais que o déficit de legitimidade acadêmica de que este padece como “objeto de estudo" recente. Parece mais, pois diríamos que sociólogos, antropólogos e cientistas políticos perceberam de forma obscura o estalido das fronteiras que a Comunicação carrega pela configuração de seus objetos móveis, nômades, de contornos difusos, impossíveis de encerrar nas malhas de um saber positivo e rigidamente parcelado. Nas transformações que emergem da experiência comunicacional há um fermento de mudanças no próprio saber. 
Mudanças de época sempre são acompanhadas por mudanças na socialidade e na cognição, o que leva Octavio Ianni (1994) a afirmar que as rupturas históricas nem sempre acarretam rupturas epistemológicas, mas quase sempre vêm acompanhadas por estas. De acordo com este autor, as Ciências Sociais são filhas de rupturas históricas - a revolução francesa e a revolução industrial - e se desenvolveram dentro do paradigma histórico-epistemológico da sociedade nacional ou da modernidade. Frente ao novo objeto, a sociedade global, as Ciências Sociais são postas diante de novos desafios históricos e epistemológicos. Nas palavras de Ianni, "muito dos seus conceitos, categorias e interpretações são postos em causa. Alguns tornam-se obsoletos, outros perdem parte de sua vigência e há os que são recriados. Mas logo se coloca o desafio de criar novos. À medida em que a realidade social passa por uma verdadeira revolução, quando o objeto das ciências sociais se transfigura, nesse contexto descortinam-se outros horizontes para o pensamento. (...) Como a problemática da globalização se encontra em processo de equacionamento empírico, metodológico e teórico, apenas começa a ser percebida em suas implicações epistemológicas, como as questões de espaço e tempo, sincronia e diacronia, micro e macro, singular e universal, individualismo e holismo, pequeno relato e grande relato" (1994:154;156).

\section{Comunicação e transdisciplinaridade}

O pensamento epistemológico no campo da Comunicação no Brasil constitui uma perspectiva recente que se manifesta no crescimento de análises auto-reflexivas . Elas têm se expressado, por exemplo, em trabalhos de reconstrução histórica do campo (Marques de Melo, Fausto Neto, Lopes, Martino) e de teorização dos objetos de pesquisa de comunicação no Brasil (Lopes, Martino, Ferrara, Sodré, Prado, Santaella, Rüdiger). Assim, dentro desse corpo sistemático de reflexões é necessário aprofundar a questão da condição disciplinar da pesquisa da Comunicação.

Desejo defender a tese de que esta preocupação epistemológica deve-se a um imperativo do momento atual. Em verdade, trata-se dos desafios cognitivos 
trazidos pelos processos de globalização e que se traduzem na chamada "crise de paradigmas".

Como novo constructo teórico- metodológico e macro-categoria das Ciências Sociais, a globalização envolve necessariamente a dialética singular-diverso e universal-global. O que implica em não priorizar um momento em detrimento do outro, mas em reconhecer que ambos se constituem reciprocamente, articulados de modo harmônico, tenso e contraditório, envolvendo múltiplas mediações

Segue-se, então, a questão que mais nos interessa. É que a reflexão sobre a sociedade global transborda os limites convencionais desta ou daquela ciência social e logo fica evidente que qualquer análise envolve necessariamente várias ciências. Os múltiplos aspectos da sociedade global põe em dúvida se ainda há algum critério que possa ser usado para assegurar, com relativa clareza e consistência, as fronteiras entre as disciplinas sociais. No dizer de Wallerstein (1990:402): “Todos os critérios presumíveis - níveis de análise, objetos, métodos, enfoques teóricos - ou não são mais verdadeiros na prática, ou, se mantidos, são obstáculos a conhecimentos posteriores, antes do que estímulos para a sua criação".

Para o campo da Comunicação, este pode ser um contexto privilegiado, a ser positivamente apropriado, uma vez que também os seus limites disciplinares são colocados em contestação, exigindo assim um olhar crítico sobre o passado da sua prática de pesquisa.

Podemos dizer que os estudos da Comunicação foram marcados desde os seus começos, entre os anos 20 e os 30, pelo paradigma de Lasswell, responsável por uma visão fragmentada e parcelar do processo de comunicação que se mantém até hoje: estudos do emissor, do canal, da mensagem e do receptor. Em cada um desses fragmentos como que houve uma "especialização" em determinados aportes disciplinares. Assim, os estudos do emissor na economia política ; os estudos do 
canal na análise tecnológica; os da mensagem na lingüística e os do receptor na sociologia ou na psicologia e, mais recentemente, na antropologia.

Acrescido a esse problema epistemológico do resgate da totalidade e da integração do processo de comunicação, a prática da pesquisa de Comunicação, segundo Moragas (1985), tem sido meramente pluridisciplinar, isto é, feita com a colaboração de distintas disciplinas para o reconhecimento de um objeto comum, cada uma delas a partir de sua ótica particular, o que leva apenas a uma justaposição de conhecimentos díspares e não à sua integração Segundo o autor, o desenvolvimento do campo caracteriza-se hoje como interdisciplinar, pois implica o confronto e o intercâmbio de métodos e pontos de vista. Para ele, um grau superior de colaboração dar-se-ia na transdisciplinaridade, etapa ainda não alcançada, que não se limitaria a posicionar um objeto comum, a compartilhar ou complementar enfoques metodológicos, senão que trabalharia com conceitos e teorias comuns às distintas ciências sociais. A solução destes problemas, para o autor, deve ser confiada à investigação epistemológica das próprias Ciências Sociais, onde se insere a Comunicação. Mas para o meio tempo, enquanto isso não acontece, Moragas faz uma proposta factível de interdisciplinaridade através do manejo da bi-disciplinaridade (psico-sociologia, economia-política, sóciolinguística) dentro do estudo de relações bipolares entre emissor-canal, mensagemreceptor, mensagem-canal, etc.

Mesmo que se discorde da proposta, o mérito de Moragas estava em proceder a uma discussão teórica sobre o estatuto disciplinar da Comunicação, e que parece estar sendo retomada depois de mais de 15 anos, agora de forma convergente, a partir de uma perspectiva epistêmica, no meio da chamada "crise dos paradigmas" das Ciências Sociais.

Um aspecto central para esse avanço é, sem dúvida, o acerto de contas da pesquisa de Comunicação com suas heranças epistêmicas positivistas, dedutivistas e funcionalistas que devem ser desmontadas criticamente para dar lugar a lógicas mais complexas e pertinentes à multidimensionalidade do objeto da Comunicação. 
É o caso do exercício do paradigma da complexidade (Morin, 1986;1991) e do paradigma do sistema-mundial (Wallerstein) ou da globalização (Ianni) nos estudos de Comunicação. Trata-se de um paradigma epistemológico transdisciplinar, porque constituído por um certo tipo de relação lógica extremamente forte entre noções mestras, noções-chave e princípios-chave das mais diversas origens disciplinares. Oposto à simplificação, Morin define paradigma da complexidade "como o conjunto de princípios de inteligibilidade que, ligados uns aos outros, poderiam determinar as condições de uma visão complexa do universo físico, biológico, antropossocial" (1986:246). Assim, segundo ele, o paradigma da complexidade não produz nem determina a inteligibilidade. Pode somente incitar a estratégia-inteligência do sujeito investigador a considerar a complexidade do problema estudado. Incita a distinguir e fazer comunicar em vez de isolar e de disjuntar, a reconhecer os traços singulares, originais, históricos do fenômeno em vez de ligá-los pura e simplesmente a determinações ou leis gerais, a conceber a unidade-multiplicidade de toda a entidade em vez de torná-la heterogênea em categorias separadas ou de homogeneizá-la numa totalidade indistinta. Incita a dar conta dos caracteres multidimensionais de toda a realidade estudada. O pensamento complexo só se manifesta à custa de uma recriação intelectual permanente, pois de outro modo arrisca-se a degradar-se, isto é, a simplificar-se. Hoje, um dos sintomas da "crise dos paradigmas" está na simplificação da teoria. Segundo Morin, a simplificação da teoria é de triplo espectro. Primeiro, ela está na degradação tecnicista, conservando-se da teoria aquilo que é operacional, manipulador, o que pode ser aplicado; a teoria deixa de ser logos para tornar-se tecné. Segundo, a simplificação esta na degradação doutrinária, pela qual a teoria torna-se doutrina, ou seja, torna-se cada vez menos capaz de abrir-se à prova da experiência, ao confronto do mundo exterior. E, terceiro, na pop-degradação, quando através da eliminação das dificuldades, reduz-se a teoria a uma fórmula de choque, à sua vulgarização.

Por outro lado, o passado das Ciências Sociais foi feito de certezas conflitantes entre si e achamo-nos num presente caracterizado por grandes questionamentos, 
os quais incluem o próprio questionamento da possibilidade intrínseca de se possuir certezas.

É ao mesmo a que se refere, em outros termos, Ilya Prigogine com o "fim das certezas" (1997).

A tônica em que insistimos vai para aquilo que é complexo, temporal, instável, e que corresponde a um movimento transdisciplinar que se afirma progressivamente. A crítica central recai sobre a artificialidade dos limites disciplinares construídos notadamente no século XIX , tanto entre os domínios das Ciências Exatas, das Ciências Sociais e das Humanidades, como entre as disciplinas dentro de cada domínio, limites esses que foram mantidos mais por tradições institucionais do que intelectuais (Wallerstein, 1996). Os desafios trazidos pela compreensão de novos objetos, como é a Comunicação, encaminham para a formação de novas sínteses disciplinares ou convergências disciplinares, isto é, de "transdisciplinas" ou "pós-disciplinas".

A possibilidade de que a Comunicação aproveite positivamente dessa e de outras maneiras as conjunturas epistemológicas e metodológicas que a "crise dos paradigmas" nas Ciências Sociais abriu, pode advir paradoxalmente do fato de ela ser um espaço de conhecimento onde a institucionalização disciplinar tem sido mais débil. Apesar das condições desfavoráveis que isso supõe, talvez daí ela tenha arrancado o sentido crítico e transformador que tem sido uma das marcas distintivas do pensamento latino-americano em Comunicação.

Entretanto, a proposta transdisciplinar tem causado tensões e polêmicas, na medida em que a institucionalização de um campo supõe sua especialização disciplinar.

A atual tendência latino-americana tem se expressado na proposta de inserir a pesquisa de Comunicação no espaço das Ciências Sociais e no desenvolvimento do enfoque sócio-cultural Aí são vistos obstáculos à delimitação de um objeto próprio e à sua legitimação acadêmica. Por isso, torna-se necessário aumentar no campo da 
Comunicação o movimento de auto-reflexividade que se espraia em todo o campo das Ciências Sociais, com particular atenção à reflexão epistemológica crítica e atualizada. Acreditamos que a prática transdisciplinar pode se produzir através de movimentos de convergências e de apropriações mútuas, tais como, a partir da Comunicação são trabalhados processos e dimensões que incorporam perguntas e saberes históricos, antropológicos, estéticos, ao mesmo tempo que a sociologia, a antropologia e a ciência política começam a se voltar, de forma não marginal, para os meios e os modos como operam as indústrias culturais.

A consciência crescente do estatuto transdisciplinar do campo permite dar conta da multidimensionalidade de que na sociedade se revestem os processos comunicativos e de sua crescente importância para a produção da modernidade em países como os da América Latina. É o que leva Martín-Barbero a afirmar que "a transdisciplinaridade de modo algum significa a dissolução dos problemasobjeto do campo da comunicação nos de outras disciplinas sociais, mas a construção de articulações - intertextualidades - que fazem possível pensar os meios e as demais indústrias culturais como matrizes de desorganização e reorganização da experiência social e da nova trama de atores e de estratégias de poder" (1996:62).

Em conclusão, o paradigma da transdisciplinaridade ou pós-disciplinaridade é conseqüência de fatores "internos" - a convergência que se nota nas modernas análises das Ciências Sociais e de fatores "externos" - o processo histórico da globalização, que se acumularam sobre o campo da Comunicação e que fazem dele "um lugar estratégico para o debate da modernidade". 


\section{Referências Bibliográficas}

CANCLINI, Néstor García, 1999. De cómo Clifford Geertz y Pierre Bourdieu llegaran al exilio. In: REGUILLO, Rossana y FUENTES, Raúl (coords.) Pensar las ciencias sociales hoy. Guadalajara: Iteso.

FUENTES NAVARRO, Raúl, 1998: La emergencia de un campo académico: continuidad utópica y estructuración científica de la investigación de la comunicación. Guadalajara: ITESO/Un.Guadalajara.

IANNI, Octavio, 1992. A sociedade global. Rio de Janeiro: Civilização Brasileira.

IANNI, Octavio, 1994: Globalização: novo paradigma das ciências sociais. Estudos Avançados, 21, São Paulo: IEA-USP.

LOPES, Maria Immacolata Vassallo, 2003. Sobre o estatuto disciplinar do campo da comunicação. In: LOPES, M.I.V. (org.). Epistemologia da comunicação. São

Paulo: Loyola.

LOPES, Maria Immacolata Vassallo, 2000. Por um paradigma transdisciplinar para 0

campo da comunicação. In: DOWBOR, Ladislau, IANNI, Octavio et al (orgs). 
Desafios da comunicação. Petrópolis: Vozes.

MARTIN-BARBERO, Jesús ,1996: Comunicación fin de siglo. Para donde vá nuestra investigación? Telos, 47, Madrid.

MARTIN-BARBERO, Jesús ,2001. Decontrución de la crítica: nuevos itinerarios de la

investigación. In. LOPES, M.I.V. e FUENTES, R. (comps.). Comunicación.Campo

y objeto de estudio. Guadalajara: ITESO.

MORAGAS, Miguel, 1985: Ubicación epistemológica e ideológica de la comunicación. In: Teorias de la Comunicación. Barcelona: G.Gili.

MORIN, Edgar, 1991: Introdução ao pensamento complexo. Lisboa: Inst. Piaget.

MORIN, Edgar, 1986: Ciência com consciência. Lisboa: Europa-América.

PRIGOGINE, Ilya , 1997. La fin de las certidumbres. Santiago de Chile: Ed. Andrés Bello.

VATTIMO, Gianni, 1992. A sociedade transparente. Lisboa: Relógio d’Água.

WALLERSTEIN, Immanuel, 1999. El legado de la sociología, la promesa de la ciencia

social. Caracas: Nueva sociedad.

WALLERSTEIN, Immanuel et al., 1996: Para abrir as ciências sociais. Lisboa: Europa- América.

WALLERSTEIN, Immanuel (1991). Unthinking social science. Cambridge: Polity Press. 
WALLERSTEIN, Immanuel, 1990: Analisis de los sistemas mundiales. In:

GIDDENS, A., TURNER, J. et al. La teoría social hoy. Madrid: Alianza 